\section{Aman Bahri,}

Service for Older People, CNWL NHS

Foundation Trust, Bentley House,

15-21 Headstone Drive, HA3 5QX.

E-mail: amanbahri@hotmail.co.uk

\section{Claire Hilton,}

Consultant Old Age Psychiatrist, CNWL NHS

Foundation Trust, Northwick Park Hospital.

\section{REFERENCES}

1. Cameron IM, Lawton K, Reid IC. Appropriateness of antidepressant prescribing: an observational study in a Scottish primary-care setting. Br J Gen Pract 2009; 59(566): 644-649.

2. Department of Health. National Service framework for older people. London: Department of Health, 2001. http://www.dh.gov.uk/dr_consum_dh/groups/dh_dig italassets/@dh/@en/documents/digitalasset/dh_40712 83.pdf (accessed 4 Dec 2009)

3. Moore M, Yuen HM, Dunn N, et al. Explaining the rise in antidepressant prescribing: a descriptive study using the general practice research database. $B M J$ 2009; 339: b3999.

4. National Collaborating Centre for Mental Health. Depression in adults (update). Depression: the treatment and management of depression in adults. London: National Institute for Health and Clinical Excellence, 2009.

http://www.nice.org.uk/nicemedia/pdf/Depression_U pdate_FULL_GUIDELINE.pdf (accessed 4 Dec 2009)

DOI: 10.3399/bjgp10X482130

\section{RCGP autumn conference}

At the close of the Royal College of General Practitioners' Annual National Primary Care Conference (Glasgow 5-7 November), the College Treasurer remarked that he had received many warm congratulations on the success of the conference, and not one adverse comment. That is not a healthy state of affairs. I am very happy to fill in online the College's evaluation questionnaire and give credit to an extremely well organised, smoothly run, professional, and indeed very enjoyable conference. We all no doubt have our favourite moments; I thought Dr Harry Burns on health inequalities was outstanding, and the highlight of the conference was the presentation on Maori health from a group based in Kaitaia, Northland, New Zealand.

However, I didn't learn any Medicine. I was very struck by the scarcity of clinical material throughout: in the plenary sessions, the concurrent streams, the fringe meetings, even, though to a lesser extent, in the poster presentations. We are obsessed with Process.

As an exercise, I have gone through the conference programme, allocating each session to one of two groups: either 'clinical' or 'non-clinical' depending both on the subject matter, and whether the speaker or panel were addressing issues of practical clinical medicine, or broader issues of policy, management, governance, process, philosophy, and so forth.

Of a total of 104 sessions, I assigned $20(19 \%)$ to the 'clinical' category, and 84 $(81 \%)$ to the 'non-clinical' category. I looked at the split as it occurred in the three types of session on offer: plenary, concurrent stream, and fringe. There were two clinical and 17 non-clinical plenary sessions ( $11 \%$ versus $89 \%$ ), 10 clinical and 46 non-clinical sessions in the concurrent streams (18\% versus $82 \%$ ), and eight clinical and 21 non-clinical fringe meetings (28\% versus $72 \%$ ). I counted a total of 132 poster presentations: 38 of these were clinical, and 94 non-clinical (29\% versus $71 \%$ ).

I would stress that I am not arguing that a clinical presentation is 'better' than a non-clinical one, nor indeed that a nonclinical presentation could not radically change the way we work; it is merely a matter of ratio and proportion: we needed more medicine.

\section{Hamish Maclaren,}

Aberfoyle Medical Practice, Main Street, Aberfoyle, Stirlingshire, FK8 3UX. E-mail: hamish.maclaren@virgin.net

DOI: 10.3399/bjgp10X482149

\section{RCGP Fellowship}

I have recently been elected a Fellow of the College, which I consider to be both a great honour and a great achievement. I had put myself forward to be considered via the Unified Route to Fellowship (http://www.rcgp.org.uk/ membership/fellowship.aspx) and I would urge all experienced and established Members to consider doing the same themselves.

It is easy to feel overshadowed by those who stand out in some particular way (who may well also put themselves forward for consideration, of course): but I know that I am not the star striker, or the demon bowler, nor the Olympic gold medal winner. No, I am a solid, dependable, all-rounder in the first team (which in my case includes everyone who works with me in the practice of which I am a partner).

The standard required for Fellowship is appropriately high, the process to be followed is rigorous, as it should be. Yet, I think that it is achievable by any Member who is committed, hardworking, aspiring to, and attaining high standards in clinical practice, or one or more other areas of general practice or primary care work. For me it involved describing what I already actually do in practice, and organising data, and other material I already had; in other words, it was not a large burden.

I think that the Unified Route to Fellowship is a good way for many colleagues like me now to receive the recognition they too deserve of their stature in the profession.

Mick Leach, GP, Harrogate. E-mail: Mick.Leach@gp-b82013.nhs.uk

DOI: 10.3399/bjgp10X482158

\section{Correction}

In the editorial: Pollock AM, Richardson L. Commercial confidentiality: a cloak for policy failure. Br J Gen Pract 2009; 59(569): 893-894, the text reads:

'At the time of writing, the NHS Choices website stated that the Department of Health is: “... taking [the seven centres] over from the independent sector ...".'

Following publication, the Department of Health has retracted this statement, as it is not planning on taking over these centres from the private sector, and will correct this information on their website.

DOI: 10.3399/bjgp09X473385 